\title{
An Approach to Develop Personality through Kundalini Yoga
}

\begin{abstract}
The objective of the study is to highlight the attributes of the personality of an individual that can be developed through the practice of various Yogic techniques. The paper is conceptual and descriptive in nature in which new insights has been explored for understanding the mechanism of Yoga for developing the personality of an individual. The paper also gives new input in understanding the integration of the concept of Spirituality and Personality that can be developed through the consistent practice of Yogasanas and breathing techniques. The four dimensions that constitute the Real Personality can be developed at physical, mental, intellectual and spiritual level for sound health, strong mind, pure intellect and spiritual growth which is possible only through the practice of Yoga. The various Yogic techniques help to induce the complete physical, mental, emotional and spiritual relaxation that enhance the personality of an individual with clear set of thoughts for achieving an individual, organizational and societal objectives. Therefore the study focuses on retaining and maintaining the individual wellbeing at various levels by developing the personality of an individual through the consistent practice of Yoga.
\end{abstract}

Keywords: Kundalini Yoga; Personality; Spirituality; Yoga; Pranayama; Chakras

\author{
Conceptual Paper \\ Volume 10 Issue 1 - 2017

\section{Manish Kumar Dwivedi*} \\ Institute of Management Studies, Banaras Hindu University, \\ India \\ *Corresponding author: Manish Kumar Dwivedi, \\ Institute of Management Studies, Banaras Hindu \\ University, India, Email: mdwivedifpm@gmail.com; \\ manishdwivedi@fmsbhu.ac.in
}

Received: June 16, 2017 | Published: December 13, 2017

\section{Introduction}

Today's world is dynamic world due to changing environmentupdating technology, innovations around the world; everyone wants to have more and more wealth. The changing needs of the people have been continuously rising day by day, people never get satisfied and want to achieve more and more. Due to this the crime rate, violence, conflicts arises within the family due to more and more demanding attitude of the people for material wealth. This unpleasant situation disturbs the peace, creating chaos, confusion and the mind reacts with jealousy, envy, hatred, anger, anxiety, sadness, depression, fear and panic. This in turn deteriorates the mental and physical heath of the people as these emotions adversely affect the physical health. The tension may eventually produce serious illness causing various diseases. The reason for all this is that they do not have controlled on their mind. Spirituality is that aspect of human existence that is concerned with 'humanness'. "It concerns the structures that give meaning and direction to a person's life and helps them to deal with the existence. It includes such vital dimensions as the quest for meaning, purpose, self transcending knowledge, meaningful relationships, love and commitment as well as for some sense of the Holy amongst us. The spiritual beliefs consists of the following elements: a sense of purpose, a sense of connectedness - to self, others, nature, 'God', a quest for wholeness, a search for hope or harmony, a belief in a higher beings, some level of transcendence or the sense that there is more to life than the material or practical, and those activities that give meaning and value to people's lives". In Ayurvedic literature, there are three important Nadis in the body named as Ida, Pingala and Sushumna. The spiritual energy can be coursing into the body when the Kundalini is awakened through the Sushumna Nadi and the energy flows inside the body. This energy controls the mind and this can be achieved through the consistent practice of Yogic techniques. This would lead to transformation of life and totally changed the personality of the human being.

Yoga

The Sanskrit word Yoga means yoke or union that is to establish a link between the spiritual aspirant and God. It is a technique by which we establish a connection with God through the synchronization of mind, body and soul. Hinduism offers many different Yogic techniques to establish control over the mind. The four most important techniques are broadly classified as:

a. Bhakti Yoga or the path of devotion. This path is meant primarily for people who are temperamentally emotional and respond easily to love and affection.

b. Jnana Yoga or the path of rational inquiry, this path primarily focuses for the people having rational temperament who have considered reasoning as appeals more than faith.

c. Raja Yoga or the path of psychic control. This is for those who are of meditative temperament with a natural yearning to completely control their mind.

d. Karma Yoga or the path of right action. They are habitually very active people.

In these approaches Raja Yoga is the most powerful technique to inculcate the spiritual powers in human being which is usually dormant in Kundalini. This Kundalini power remains asleep near the lower extremity of the backbone. The human backbone has 
in it three extremely narrow channels. There are two vertical channels side by side, the vital energy or nerve current of a person will work in the body by passing through these two channels. The left channel is called Ida and the right channel Pingala. If a person's breath is stronger through the left nostril when exhaling, it is an indication that the vital energy is flowing through the Ida channel. Similarly if the outgoing breath is stronger through the right nostril, the energy is flowing through the Pingala channel. When a person is doing a lot of physical activity, energy flows through the Pingala channel. When resting, energy flows through the Ida channel. There is a third narrow channel between the Ida and Pingala. Its name is Sushumna. Normally the Sushumna channel remains closed at the bottom. It opens up when the Kundalini is awakened. The Kundalini can be awakened with the consistence practice of Kundalini Yoga. The awakened Kundalini begins coursing through the Sushumna channel towards the brain. The spiritual aspirants enter into the different domains of experience and starts feeling spiritual experiences. When the awakened Kundalini starts moving towards the brain, it seems to pass through different doors through Meditation and the other spiritual disciplines of Raja Yoga. Each door or level of spiritual experience is called Chakra.

Raja Yoga consist of seven level of Chakras at the top level is located Sahasrara which is located inside the brain. The lowest one, at the lower end of the spinal cord is Muladhara. The next higher Chakra is Swadhishthana, Then in succession come Manipur, Anahata, Vishuddha, Ajna and Sahasrara. The dreams, thoughts and imagining exist in Chittakasha or mental space. All spiritual experiences take place in Chidakasha or Knowledge space. Chidakasha can get be accessed only when Kundalini power has awakened and entered into the Suhumna channel. All experiences in mental space (Chidakasha) are imagined. When the Kundalini power enters through the Sushumna channel and reaches the Sahasrara, we become spiritually illuminated. This involves the dispersion of spiritual energy at all levels in the body.

Meditation raises the Kundalini Shakti from Mooladhara to the Agnya Chakra. It improves the awareness and will power of the people. It improves the memory power and relaxes the body and mind. With the regular practice of Yoga, an individual learn to tap into the source of energy himself. It is just a manifestation of the vast pool of energy that's moving the entire universe, known as Prana. An Asana practice does that, but a Pranayama practice permeates the energy level in the body. Prana is the energy dispersed in the universe at all levels in the physical, mental, intellectual, sexual, spiritual and cosmic energy, vigour, power, vitality, life and spirit are all forms of Prana.

At its deepest level, Yoga involves generating energy. But through Yoga, you can actually change its quality and generate more of it, by enlarging the body's capacity as an energy transformer. Everyone has experienced different qualities of energy. Yoga postures energize and oxygenate the whole body thus enhancing the performance of all the organs. Yoga is essential for the betterment of health and well-being, gives greater control of your mind and a greater understanding of finding the solutions of the problems by the awakened Kundalini. This helps to identify yourself and leads to the transformation of life. Yama, Niyama, Asanas, Pranayama, Pratyahara, Dharana, Dhyana and Samidhi are the eight steps of the Yogic practices, which contribute to the mental fitness of the practitioner. Yama is all about moral principles, Niyama is about introspection and contentment, Asanas related to physical postures, Pranayam focus on control of Pranas, Pratyahara is withdrawal of the senses,Dharana focuses on awareness and Dhyana is all about meditation. These yogic practices help to develop the overall personality as it elevates your mind to a higher level (Figure 1).

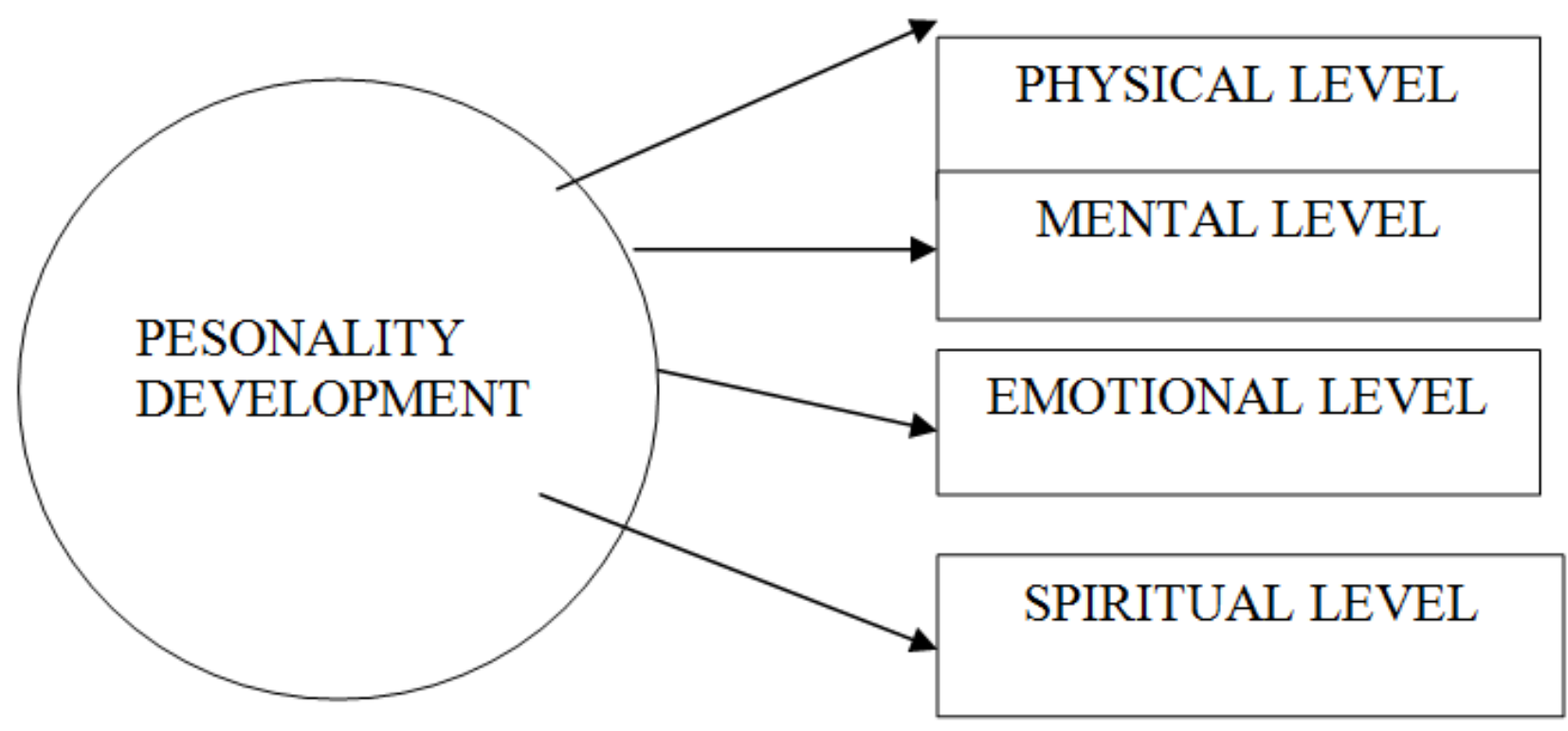

Figure 1: Conceptual Model of Developing the Personality through Spiritual energy. 
Yoga helps to develop the personality of an individual at the following levels

a. Physical level: Yoga is the most effective method to keep the body fit and work more efficiently towards achieving the goal of life by directing the energies in the most controlled manner.

b. Mental health: Boost the power of imagination, creativity and will power of the mind. Develop the sharpness of mind and make the person more intellect with the help of Mediation.

c. Emotional level: Control, sensitize and neutralizes the emotions like anger, hatred, jealousy, envy etc. and eradicate worries.

d. Spiritual level: The spiritual energy can be awakened through the Kundalini which passes through the Sushumna channel into the brain and makes the life full of enthusiasm and having a purpose of meaning in life. Introspection is necessary to improve the character of an individual to get enlighten and to enjoy peaceful and happy life.

Yoga is not just an art. It is science and life style. Maintaining perfect health, proper mental development and ability to manage emotions are essential to improve personality. Yoga provides all this and more. It keeps you balanced and composed, it alleviates the physical sufferings, mental stress and negative thoughts. It helps to keep an individual focused and ultimately leads a person to enjoy perfect harmony. Thus, including Yoga in day to day life can enhance the personality. As Yoga and breathing techniques stimulate right and left brains, the overall performance of the human beings improves, which gives personality a great boost. Yoga helps you to identify the inner self so that your life and perceptions get elevated to a higher plane.

Meditation is one of the techniques of Yoga which supply electricity to a whole body like a light bulb. Meditation is quite like the act of switching on the supply. It helps us tap an endless reservoir of energy that we are made of. When we get in touch with our energy core, our filament-like self gets charged, and that radiates as the charming qualities of our personality-both physical and mental. It is that changing dysfunctional habits is largely a matter of the mind. It burns old Samskaaras, habits and tendencies and inculcates the new habits. It would help to maintain the peace and harmony among the individuals. It transforms the whole personality and develop positive attitude towards life. Personality comprises of behavior, attitude, emotional balance and positive approach. A strong personality exhibits confidence. Personality development is developing skills relevant to make the life happy and successful. One could achieve body and mind co-ordination if an individual practice Yoga regularly. Yoga not only helps to keep the body physically fit but it also helps to keep an individual mentally fit and focused. Yoga and breathing practices activate the brain and improve the performance of the brain. Yoga enhances memory power as well. The concentration level improves with Yoga practices and this would help in understanding and perceive the things in a better way.

Yoga will be able to find the strength, confidence, presence, and discipline in life for making him better human being. It inspires an individual to create awareness about himself and others. Being emotionally charged does not help a person to handle things better. If a person maintains a state of calm while facing tough times, it would help an individual being able to make better decisions in life. Yoga helps to maintain the body for keeping calm and composed and thus would also assist in making a decision in an effective manner at the time of trouble [1-4].

\section{Development of personality traits through meditation}

It helps to develop the traits of the human beings which is essential for the development of the personality through Yogic techniques:-

a. Confidence: Meditation can make an individual to learn and live in a present moment rather than past and future. A person is more focused and powerful, feel confident and courageous towards an achieving his goals. It also inculcates the feeling of self-disciple among the practitioner thus contributing to the development of personality.

b. Stress reliever: Yoga alleviates stress thus enhances the clarity of thoughts to think clearly for finding the solution of the problem in his life. It keeps a person stress-free and helps him to handle things in a better way. Clarity of thinking makes it possible to take right decisions and come to right judgment.

c. Optimism: The various doubts about an individual's efforts or capabilities bring negativity in mind. There is a way to break this vicious cycle of negative thoughts from which a person gets rid of is Meditation.(Priya Rao) Meditation pumps energy in the body and high energy is a sign of positivity. The doubts and negative thoughts go away from the mind when he adopts positive approach in his life by practicing of breathing exercises and yoga asanas which can change the outlook towards life. It helps to find the opportunities in challenges which is another dimension of making appropriate decision at the time of trouble.

d. Discovering your life's purpose: Yoga makes the life more meaningful as it discovers the life's purpose towards achieving an objective at the workplace and personal level. When someone is happy, he/she can achieve his objective more efficiently that reflects in the personality of an individual.

e. Compassion: Yoga nurtures the seed of compassion that's already there. "Accepting that everyone, including us, has flaws helps us love ourselves", (Radhika Srivastava). An undying spirit of enthusiasm ensures success in the long term and shines through our personality. And a person who is soft on himself and others is always a pleasure to be around.

f. Communicating effectively: Meditation brings clarity in thoughts and intellect and helps us perceive situations with precision. A person is therefore able to express ourselves in a way that makes sense and base his decisions on sound facts.

g. Appreciating others' efforts: In Meditation, prejudiced thoughts can be overcome which do not allow us to connect 
with the other person. When a person is able to transcend such thoughts, a sense of belongingness and caring develops and we start appreciating even their smallest efforts. "When the appreciation is coming straight from the heart, it will definitely touch the other person. This way, Meditation brings out the best in us and also in others, and makes us a friendlier person".(Priya Rao)This helps an individual to develop better interpersonal relation with others..

h. Making sound decisions: "Meditation refines our thoughts and intuition. It also controls and settled the emotions and brings sharpness of intellect. This helps us in making sound decisions"

i. Equanimity: "A meditator develops a positive perception of the bad situation also, doesn't get swayed by it and take it as an opportunity. It brings the wisdom that both the good and the bad times shall pass. And the only thing that's permanent is change" (Radhika Srivastava). This attitude makes you friendly and cheerful. This, on the whole, reflects in your personality.

j. Physical appearances: Meditation helps a person to glow. This is due to the release of stress from each cell's memory and gives a person's skin a direct boost of energy. When an individual look beautiful naturally, he tends to feel more confident about himself, and that shows in the way he carry himself. He is able to create an impression in the minds and hearts of people around him.

\section{Conclusion}

Yoga plays an important role in the development of personality of human being. It maintains the balance between the mind, body and soul by awakening the spiritual spirit and coursing the flow of energy throughout the body. That releases the stress from the body and makes the mind and the body calmer. It helps to develop the various personality traits such as a person feels more confident, identify his strength, take the decisions more accurately, make discrimination between right and wrong, communicate effectively with clarity of thought, identify the self, hope to lead a positive happy life. This would help to get rid off from the diseases and maintain the peace, harmony and prosperity in the country. Developing spiritual spirit through Yogic techniques would help to develop positive outlook towards life and in turn can accomplish the objective of life more efficiently.

\section{Acknowledgment}

None.

\section{Conflict of Interest}

The author declares that there is no conflict of interest.

\section{References}

1. Bhaskarananda, Swami (1996) Meditation Mind and Patanjali's Yoga. Sri Ramakrishna Math. Chennai, India, pp. 123-125.

2. Cornah, Deborah (2006) The impact of spirituality on mental health. Mental Health Foundation. p. 6

3. Krishnan, Sripriya (2006) Personality Development through Yoga practice. Indian Journal of Traditional Knowledge 5(4): 445-449.

4. Srikantantananda S (2015) What is Real Personality. Adhyaksha Ramakrishna Math, Hyderabad, India, p. 1-23.

5. Vivekanand S (2015) Personality Development. Swami Tattwavidananda Adhyaksha Nagpur, India, p. 10-21. 